\title{
A CORRELATIVE CYTOLOGICAL AND HISTOPATHOLOGICAL STUDY ON LESIONS OF THYROID GLAND
}

\author{
Sivaelagovan $R^{1}$, Malliga $S^{2}$, A. Veni Alagamuthu ${ }^{3}$
}

\author{
${ }_{1}^{1}$ Assistant Professor, Department of Pathology, KAPV Government Medical College/MGM Government Hospital, Trichy, Tamilnadu, \\ India. \\ ${ }^{2}$ Associate Professor, Department of Pathology, Sivagangai Government Medical College, Sivagangai, Tamilnadu, India. \\ ${ }_{3}^{3}$ Assistant Professor, Department of Neurology, KAPV Government Medical College/MGM Government Hospital, Trichy, Tamilnadu, \\ India.
}

\section{BACKGROUND}

\section{ABSTRACT}

Thyroid gland is affected by a variety of pathological lesions. Fine needle aspiration cytology is a safe as well as cost effective tool in the study of thyroid lesions. Observations strongly support that Fine Needle Aspiration Cytology should be the initial investigation for thyroid disease. This study was conducted to find out the diagnostic ability of the FNAC (Fine Needle Aspiration Cytology) in detecting malignant neoplasm in comparison with histopathology.

\section{METHODS}

A diagnostic evaluation study was conducted in the Department of Pathology, Madurai Medical College, Madurai. A correlative study between Fine Needle Aspiration Cytology and histopathology was done for 117 cases. A range of cytological diagnosis was offered on all satisfactory smears. Finally, the results of FNAC and the histopathology were compared for all the 117 cases.

\section{RESULTS}

Sensitivity, specificity, positive predictive value (PPV), negative predictive value(NPV), and diagnostic accuracy for malignant lesions of thyroid were 58\%, 98\%, 85\%, 92\% and 91.45\% respectively. Our study results were correlating with those of other studies.

\section{CONCLUSIONS}

Fine Needle Aspiration Cytology is a cost effective, simple, rapid, almost non-invasive, and an efficient method in differentiating benign and malignant lesions. With the aid of FNAC, unnecessary surgical procedures can be reduced.

HOW TO CITE THIS ARTICLE: Sivaelagovan R, Malliga S, Alagamuthu AV. A correlative cytological and histopathological study on lesions of thyroid gland. J. Evolution Med. Dent. Sci. 2019;8(13):1049-1055, DOI: 10.14260/jemds/2019/232

\section{BACKGROUND}

The Thyroid gland is unique among the endocrine glands. It is the largest of all the endocrine glands and it is superficial in location. It is the only gland which is easily approachable to direct physical and cytological examination. The thyroid gland is affected by a variety of pathological lesions that are manifested by various morphologies including developmental, inflammatory, hyperplastic and neoplastic pathology which are quite common in the clinical practice. Lesions of thyroid are so common, and it presents as diffuse enlargement or solitary or multiple nodules. The Incidence of malignancy presenting on thyroid lesion is quite low when compared with the overall incidence of thyroid nodular lesions. Emphasis is placed upon to find diagnostic modalities that may improve the ability to differentiate between nonneoplastic and neoplastic lesions and differentiation of benign and malignant lesions. There is continuous discussion for appropriate interpretation and management of thyroid lesions. A need to address these arguments and to provide a clinically applicable with cost effective approach to the evaluation of thyroid lesions and its management has prompted to take up this study.

'Financial or Other Competing Interest': None.

Submission 03-03-2019, Peer Review 23-03-2019,

Acceptance 26-03-2019, Published 01-04-2019.

Corresponding Author:

Dr. Malliga S,

Associate Professor, Department of Pathology,

Sivagangai Government Medical College,

Sivagangai, Tamilnadu, India.

E-mail: lakshaelango@gmail.com

DOI: $10.14260 /$ jemds $/ 2019 / 232$
Fine needle aspiration cytology is a safe as well as cost effective tool in the study of thyroid lesions. Observations strongly support that Fine needle aspiration cytology should be the initial investigation of thyroid disease. We also studied the incidence in relevance to age, sex in various categories of thyroid lesions. In this study we have evaluated the accuracy of Fine needle aspiration cytology correlation with histopathological study.

Fine Needle Aspiration Cytology has been established as the investigation of choice in thyroid lesions. It has excellent patient compliance, simple and quick to perform in outpatient department and is cost effective with high degree of sensitivity and specificity. Fine Needle Aspiration cytology is almost non-invasive and an efficient method in differentiating benign and malignant thyroid lesions there by unnecessary surgical procedures can be reduced. Hence the study was conducted to find out the diagnostic ability of the FNAC (Fine Needle Aspiration Cytology) in detecting malignant neoplasm in comparison with histopathology.

\section{METHODS}

A diagnostic evaluation study was conducted in the Department of pathology, Madurai Medical College, Madurai. A total of 1123 head and neck lesions were received during the study period. Out of these, 926 were thyroid lesions. Among these thyroid lesions, 117 cases had post-surgical follow up. The detailed clinical history of these 117 patients including the duration of swelling, pain, fever, loss of weight, loss of appetite and cough with expectoration, etc. were obtained. A correlative study between Fine Needle Aspiration Cytology and histopathology was done for these 117 cases. A range of cytological diagnosis was offered on all satisfactory 
smears. The surgery was conducted based on the results of the FNAC and the specimens were collected. Then all the specimens were undergone the gold standard histopathological examination. Finally, the results of FNAC and the histopathology were compared for all the 117 cases.

\section{FNAC}

In Fine Needle Aspiration Cytology, the syringes used were 5$10 \mathrm{ml}$ and the needle size between 22-23 gauges. The cytological materials obtained were fixed in ninety-five (95\%) ethyl alcohol then stained with haematoxylin and eosin.

\section{Histopathology}

The specimens of lobectomy, hemi-thyroidectomy, near total thyroidectomy and total thyroidectomy with modified neck dissection were received for histopathological examination. The specimens were fixed in 10\% formalin for $24-48$ hours. Then detailed gross examination including weight, measurement, shape, colour and consistency were noted. They were cut into parallel and longitudinal slices including the capsular invading areas. The additional features such as haemorrhage, cystic degeneration, calcification, necrosis and distance from the line of resection were noted.

\section{Statistical Analysis}

All the collected information was entered in excel sheet and the analysis was done using Epidemiological Information Package (EPI). Descriptive statistics were done to express the age, sex. To assess the diagnostic ability of the FNAC in various parameters like sensitivity, specificity, positive predictive value, negative predictive value and accuracy were calculated. The following formulas were used to calculate various parameters. (Sensitivity=True positive x 100/True positive + False negative, Specificity=True negative $\mathrm{x}$ $100 /$ False positive + True negative, Positive predictive value $=$ True positive $\mathrm{x} 100 /$ True positive + False positive, Negative predictive value $=$ True negative $x 100 /$ True negative + False negative, Accuracy=True positive + True negative $x$ $100 \mathrm{~N})$.

\section{Ethical Issues}

To conduct the study permission was obtained from various department including Department of surgery, Department of Ear, nose and Throat, Department of surgical oncology. Informed written consent was obtained from all the study participants before doing FNAC. Ethical clearance was obtained from Institutional Ethical Committee, Madurai medical College.

\section{RESULTS}

\section{Sex Distribution}

A total of 117 patients / specimens were included. There were 8 Males (6.8\%) and 109 females (93.2\%) in the study.

\section{Age Distribution}

The mean (SD) age of the study population was found to be 39.8 years (13.3 years). In the present study, the youngest patient was fifteen years old and oldest patient was seventy years old. Maximum number of participants were found to be in the age group of 21 to 30 years (29\%) (Table- 1),

\begin{tabular}{|c|c|c|}
\hline \multirow{2}{*}{ Age Group (in Years) } & \multicolumn{2}{|c|}{ Cases } \\
\cline { 2 - 3 } & No. & $\mathbf{\%}$ \\
\hline Up to 20 Years & 4 & 3.4 \\
\hline 21-30 Years & 34 & 29.0 \\
\hline 31-40 Years & 25 & 21.4 \\
\hline 41-50 Years & 27 & 23.1 \\
\hline Above 50 Years & 27 & 23.1 \\
\hline Total & $\mathbf{1 1 7}$ & $\mathbf{1 0 0}$ \\
\hline \multicolumn{2}{|c|}{ Table 1. Age Distribution } \\
\hline
\end{tabular}

\section{FNAC Diagnosis}

Out of these 117 FNAC studies, eighty one cases were reported as nodular goiter(69.23\%),twelve cases as papillary carcinoma $(10.3 \%)$, Nine cases as Hashimoto's thyroiditis (7.7\%), Five cases as Lymphocytic thyroiditis (4.3\%), Eight cases as follicular neoplasm (6.8\%),one case as Granulomatous thyroiditis $(0.85 \%)$ and another one case as anaplastic carcinoma (0.85\%).

Out of these 117 specimens, 73 cases were reported as Non-neoplastic Lesions, (62\%) 44 cases as neoplastic lesions (38\%), Out of these 73 Non-neoplastic Lesions cases, 54 were reported as Nodular goiter. 18 were reported as Hashimoto's thyroiditis, one was reported as Granulomatous thyroiditis. Out of the 44 neoplastic lesions 25 cases were reported as benign neoplastic lesions and 19 as malignant neoplastic lesions. Among the 19 malignant neoplastic lesions 16 cases were reported as papillary carcinoma, 2 cases as medullary carcinoma thyroid and 1 case as anaplastic carcinoma.

\section{Correlation Between FNAC and Histopathology}

In the present study 81 cases of Nodular goiter on Fine Needle Aspiration cytology were found to be Nodular goiter in 45 cases (Fig. 6, 7, 8), Follicular adenoma in 20 cases, Hashimoto's thyroiditis in 10 cases, Papillary carcinoma in five cases and Medullary carcinoma in one case on subsequent histopathological examination.

Five cases of Lymphocytic thyroiditis on Fine Needle Aspiration cytology were found to be Nodular goiter in one case, Follicular adenoma in two cases and Hashimoto's thyroiditis in two cases on subsequent histopathological examination.

Eight cases of Follicular neoplasm on Fine Needle Aspiration cytology were found to be Nodular goiter in five cases and Follicular adenoma in three cases on subsequent histopathological examination (Fig. 9, 10, 11).

Nine cases of Hashimoto's thyroiditis on Fine Needle Aspiration cytology were found to be Hashimoto's thyroiditis in five cases (Fig. 3, 4, 5), Nodular goiter in two cases, medullary carcinoma in one case and papillary carcinoma in one case on subsequent histopathological examination.

Twelve cases of Papillary carcinoma on Fine Needle Aspiration cytology were found to be Papillary carcinoma in ten cases (Fig 12, 13, 14, 15, 16, 17), Hashimoto's thyroiditis in one case and Nodular goiter in one case on subsequent histopathological examination.

One case of anaplastic carcinoma (Fig. 18, 19) and another one case of Granulomatous thyroiditis on Fine Needle Aspiration cytology were confirmed by subsequent histopathological examination (Fig. 1, 2). In the present study, sensitivity, specificity, positive predictive value, negative predictive value, positive LR, negative LR, accuracy was found to be $58 \%$ (95\% CI: $34 \%$ to $80 \%$ ), $98 \%$ (95\% CI: $93 \%$ to 99\%), 85\% (95\% CI: 57 to $-96 \%$ ), $92 \%$ (95\% CI: $87 \%$ to 
96\%),28.37(95\% CI 6.83 to 117.87), 0.43 (95\% CI 0.25 to 0.73 ), $91.45 \%$ (95\% CI: $84.84 \%$ to $95.83 \%$ ) respectively and were calculated using the following table-2.

\begin{tabular}{|c|c|c|c|c|}
\hline \multicolumn{4}{|c|}{ Histopathological } & \multirow{2}{*}{ Tota } \\
\hline \multirow{3}{*}{ FNAC } & & Positive & Negative & \\
\hline & Positive & 11 & 2 & 13 \\
\hline & Negative & 8 & 96 & 104 \\
\hline \multicolumn{2}{|c|}{ Total } & 19 & 98 & 117 \\
\hline \multicolumn{5}{|c|}{ Table 2} \\
\hline
\end{tabular}

\section{DISCUSSION}

Fine Needle Aspiration Cytology of thyroid has become the most common and well established preoperative diagnostic procedure used in the management of patients with thyroid lesions. It is relatively cost-effective procedure that provide diagnosis rapidly.

\section{Incidence of Thyroid Lesions}

We received 117 gross specimens for histopathological examination following initial cytological evaluation by fine needle aspiration cytology. In present study non neoplastic lesions accounts for seventy-three cases and neoplastic lesions accounts for forty-four cases. The ratio between non neoplastic and neoplastic thyroid lesions in this study is 1.66:1. Incidence of non-neoplastic and neoplastic thyroid lesions in this study is tabulated in table number 3.

\begin{tabular}{|c|c|c|c|c|}
\hline Sl. No. & Studies & $\begin{array}{c}\text { Non- } \\
\text { Neoplastic }\end{array}$ & Neoplastic & Ratio \\
\hline 1. & Pepper G.M 1 & 84 & 18 & $4.66: 1$ \\
\hline 2. & Dorairajan N & 78 & 20 & $3.90: 1$ \\
\hline 4. & Naggada HA $^{3}$ & 51 & 18 & $2.83: 1$ \\
\hline 5. & Gupta C & 470 & 30 & $15.66: 1$ \\
\hline 6. & Kaur K & 32 & 15 & $2.13: 1$ \\
\hline 7. & Due k SD & 145 & 61 & $2.37: 1$ \\
\hline 8. & $\begin{array}{c}\text { Hurtado - Lopez } \\
\text { LM }\end{array}$ & 80 & 50 & $1.60: 1$ \\
\hline 10. & Prakash H.M 7 & 138 & 24 & $5.75: 1$ \\
\hline 11. & Present Study & 73 & 44 & $1.66: 1$ \\
\hline \multicolumn{4}{|c|}{ Table 3. Incidence of Thyroid Lesions } \\
\hline \multicolumn{4}{|c}{} \\
\hline
\end{tabular}

\section{Incidence of Malignancy}

In the present study, the incidence of malignant neoplastic thyroid lesions accounts for $16.24 \%$ which well correlates with studies conducted by various research workers as well as in literature and tabulated in the Table number -4 .

\begin{tabular}{|c|c|c|}
\hline Sl. No. & Study & Percentage \\
\hline 1. & Mary Jo Welker et al ${ }^{8}$ & $5-10 \%$ \\
\hline 2. & Kaur et al ${ }^{5}$ & $18 \%$ \\
\hline 3. & YS Chenug et al $^{9}$ & $5-10 \%$ \\
\hline 4. & Munsad B et al ${ }^{10}$ & $4.16 \%$ \\
\hline 5. & Suresh et al ${ }^{11}$ & $10 \%$ \\
\hline 6. & GG Swamy et al 12 & $18.33 \%$ \\
\hline 7. & Prakash H.M7 & $14.81 \%$ \\
\hline 8. & present study & $16.24 \%$ \\
\hline \multicolumn{3}{|c|}{ Table 4. Incidence of Malignancy } \\
\hline
\end{tabular}

\section{Age Incidence}

In the present study the mean age of presentation is 39.8 years which correlates with the literature of various authors and tabulated in table number -5 .

\begin{tabular}{|c|c|c|}
\hline Sl. No. & Studies & Mean Age \\
\hline 1. & ${\text { Prakash HM et } \mathrm{al}^{7}}^{7}$ & 35.67 Years \\
\hline 2. & ${\text { Manoj Gupta et } \mathrm{al}^{13}}{ }^{13}$ & 38.7 Years \\
\hline 3. & ${\text { Martin et } \mathrm{al}^{14}}^{4}$ & 39.5 Years \\
\hline 4. & Present Study & 39.8 Years \\
\hline \multicolumn{2}{|c|}{ Table 5. Comparative Incidence of Mean Age in Different } \\
Studies
\end{tabular}

\section{Sex Incidence}

In this study, majority of them were females. Female to male ratio of 13.6: 1 and correlates with observation of other various authors as indicated in table number- 6 .

\begin{tabular}{|c|c|c|}
\hline Sl. No. & Studies & $\begin{array}{c}\text { Sex Incidence } \\
\text { (Female: Male) Ratio }\end{array}$ \\
\hline 1. & Das DK 5 & $5.39: 1$ \\
\hline 2. & Manoj Gupta 13 & $11: 1$ \\
\hline 3. & Martin etal ${ }^{4}$ & $6.4: 1$ \\
\hline 4. & Prakash H.M 7 & $7.1: 1$ \\
\hline 5. & Dorairajan N ${ }^{2}$ & $9: 1$ \\
\hline 6. & Present Study & $13.6: 1$ \\
\hline Table 6. Comparative Sex Incidence of Thyroid Lesions in \\
Different Studies \\
\hline
\end{tabular}

\section{Concordance Between FNAC and Histopathology}

In the present study sensitivity, specificity, positive predictive value (PPV), negative predictive value (NPV), diagnostic accuracy for malignant lesions of thyroid were 58\%98\%85\%,92\%,91.45\% respectively. The following table (Table 7) shows the comparison of specificity, sensitivity and diagnostic accuracy for malignant lesions of thyroid with various authors and is correlating well.

\begin{tabular}{|c|c|c|}
\hline $\begin{array}{r}\text { Sl. } \\
\text { No. }\end{array}$ & Studies & $\begin{array}{c}\text { Concordance Between } \\
\text { FNAC and Histopathology }\end{array}$ \\
\hline 1 & Harach et al $^{15}$ & $58.30 \%$ \\
\hline 3 & Kunori et al $^{16}$ & $98.00 \%$ \\
\hline 4 & Das et al $^{5}$ & $90.00 \%$ \\
\hline 5 & Hag et al $^{17}$ & $91.40 \%$ \\
\hline 6 & Sandeep R Mathur et al 18 & $97.01 \%$ \\
\hline 7 & Present Study & $91.45 \%$ \\
\hline \multicolumn{2}{|c|}{ Table 7 } \\
\hline
\end{tabular}

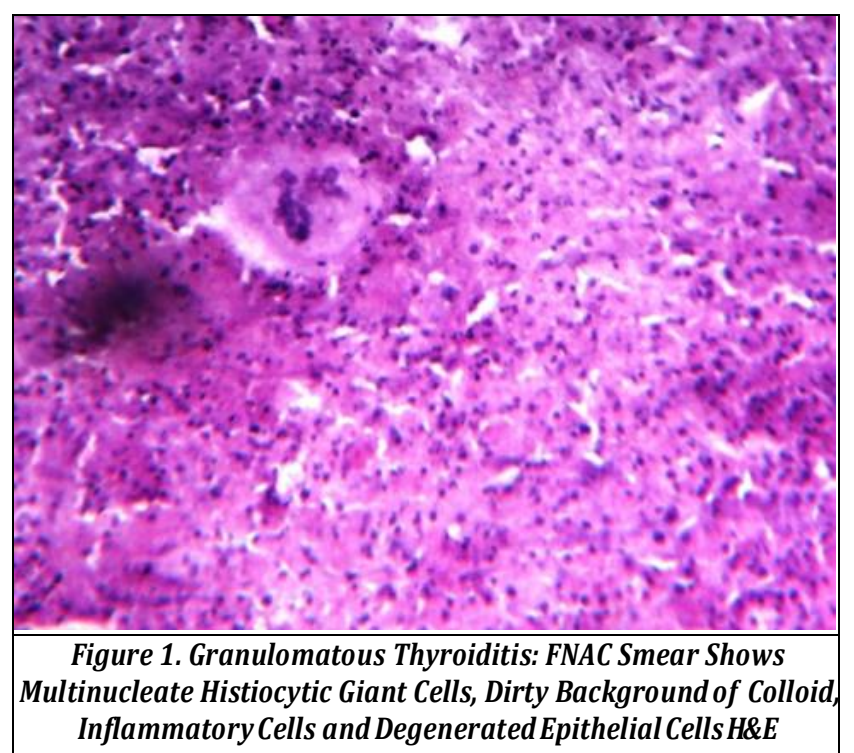




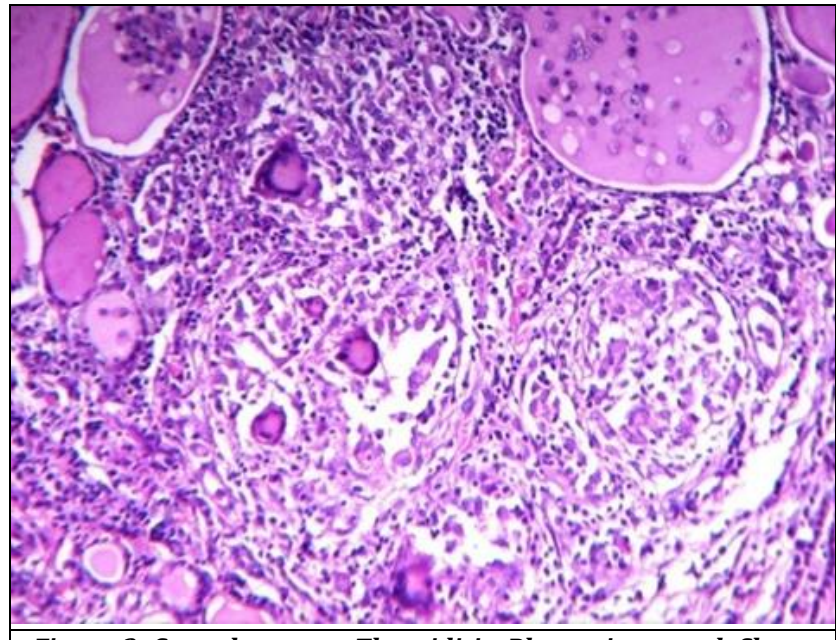

Figure 2. Granulomatous Thyroiditis: Photomicrograph Shows Macrophages, Plasma Cells about Collapsed and Damaged Thyroid Follicles and Multinucleate giant Cells. H\&E

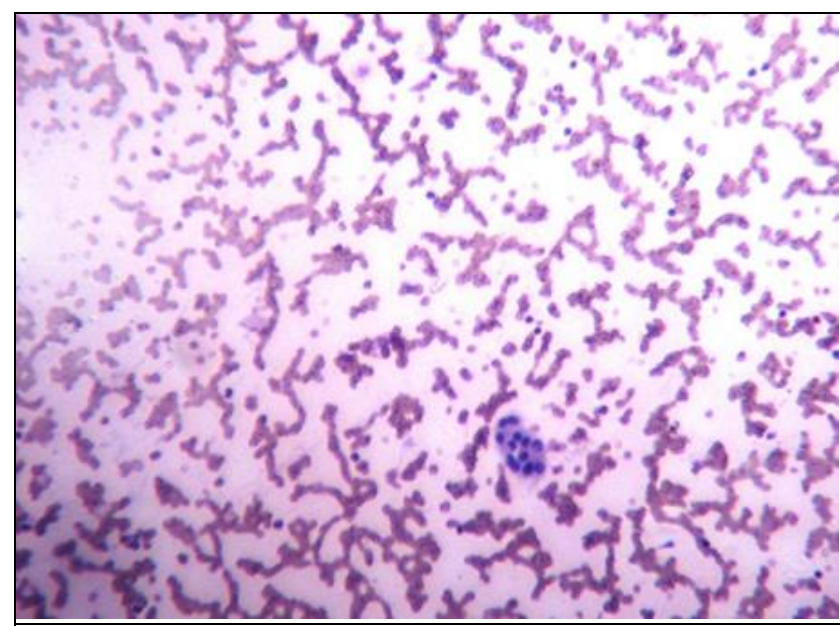

Figure 3. Hashimoto Thyroiditis: Photomicrograph-FNAC Smear Shows Hurthle Cells. H\&E

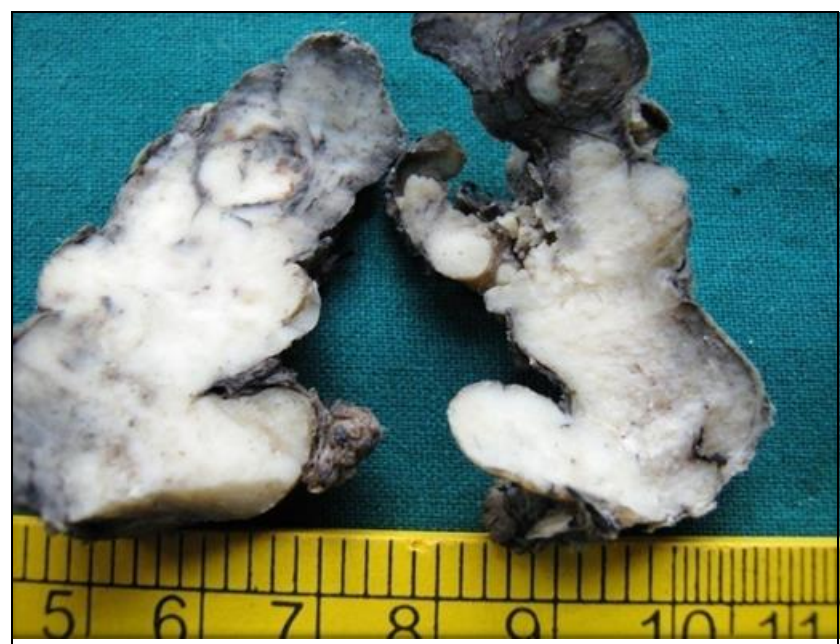

Figure 4. Hashimoto's Thyroiditis: Cut Surface is Pale, Yellow Tan in Appearance. Gross Specimen.

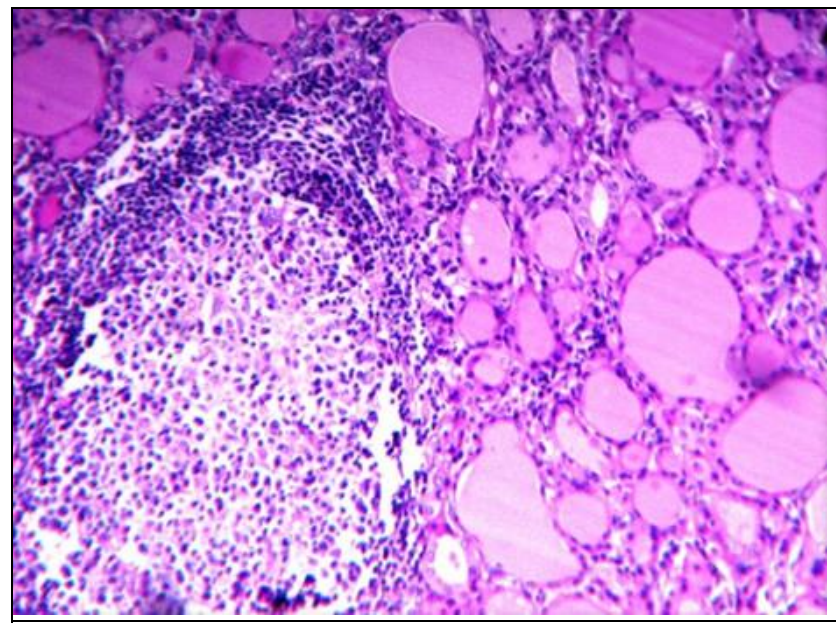

Figure-5. Hashimoto Thyroiditis: Photomicrograph Shows Infiltration of the Parenchyma by Mononuclear Inflammatory Infiltrate and Well-Developed Germinal Center (H\&E)

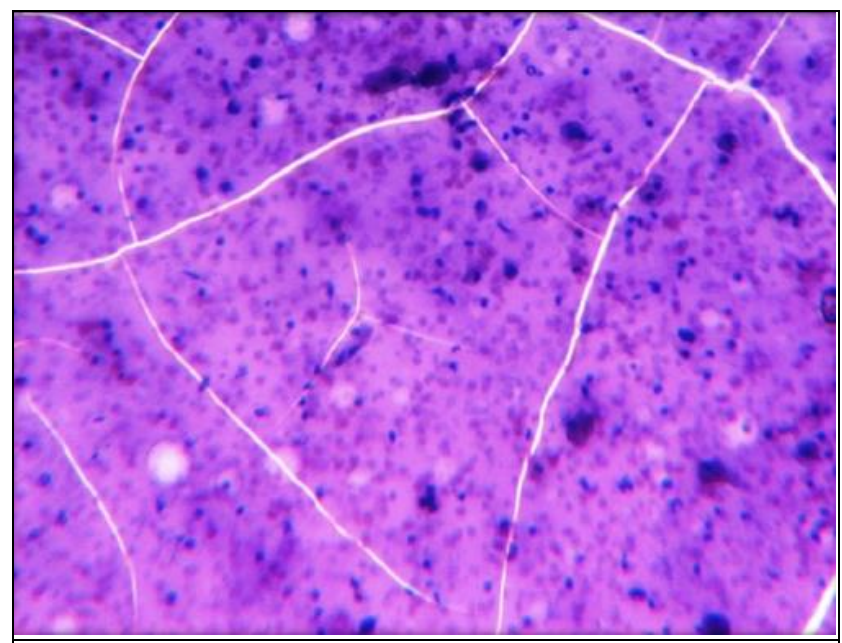

Figure 6. FNAC-Smear Showing Follicular Epithelial Cells in Background of Colloid H \& E

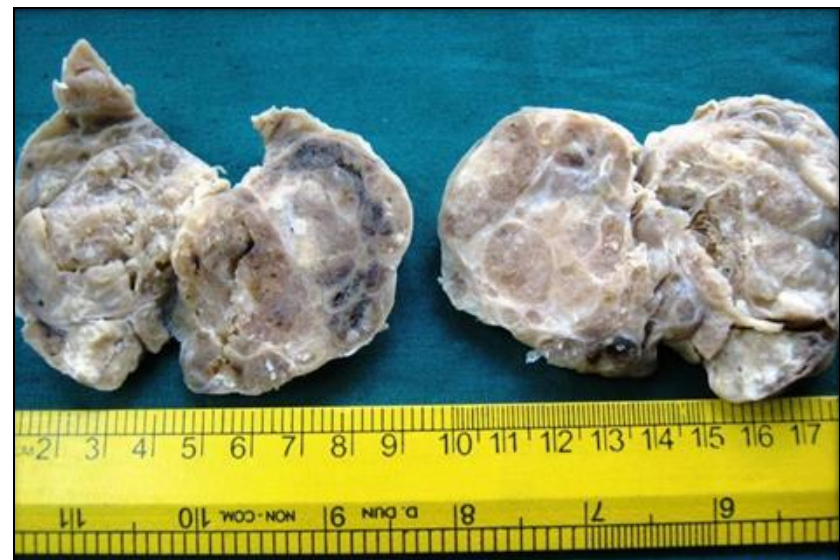

Figure 7. Multi nodular Goiter: Gross Morphology Showing a Coarsely Nodular Gland with Areas of Fibrosis and Cystic Change. GrossSpecimen 

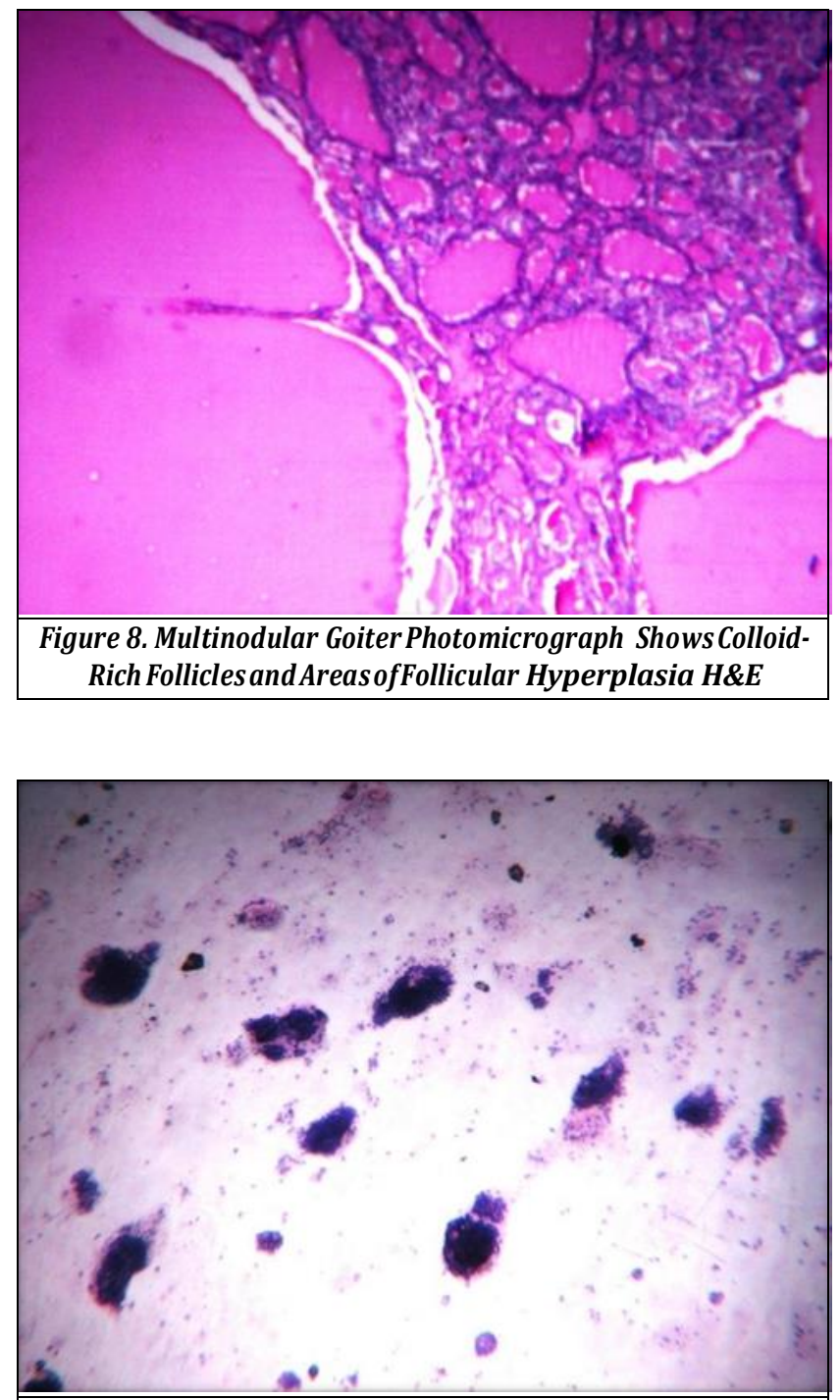

Figure 9. Follicularneoplasm: FNACSmearShowing Follicular Epithelial Cells Arranged in Repetitive FollicularPattern. H\&E

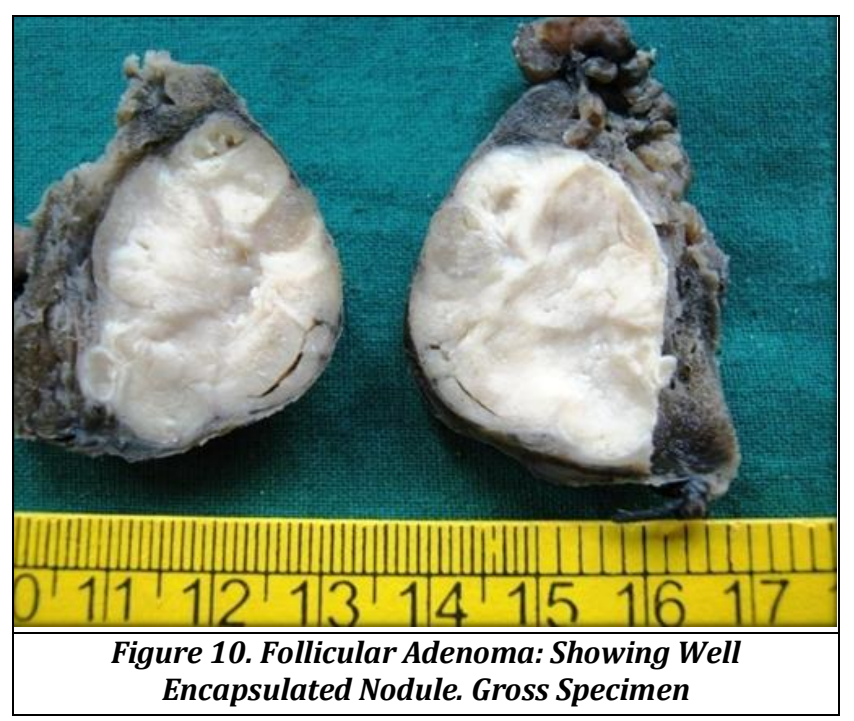

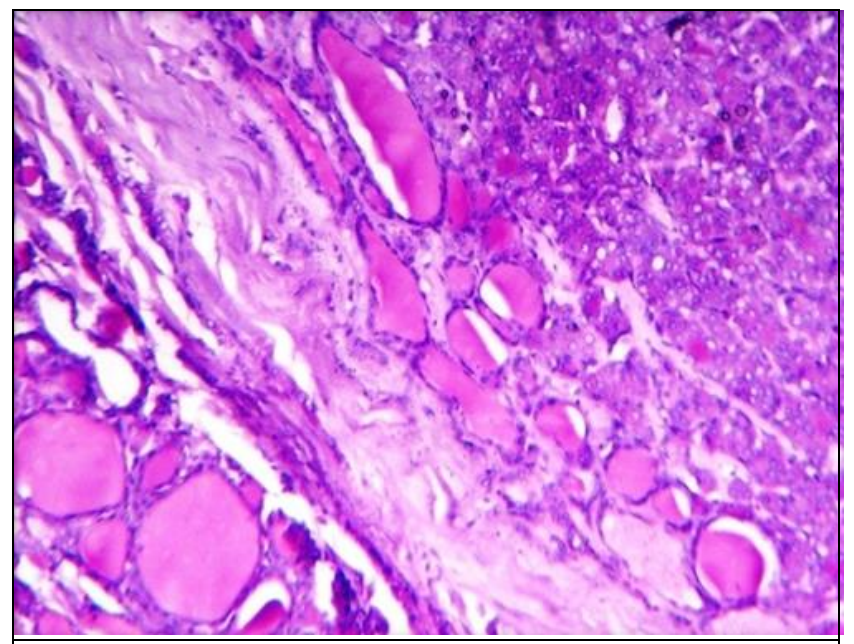

Figure 11. Follicular Adenoma:Photomicrograph Shows Well Formed Capsule Encircling the Tumor $\mathrm{H} \& \mathrm{E}$

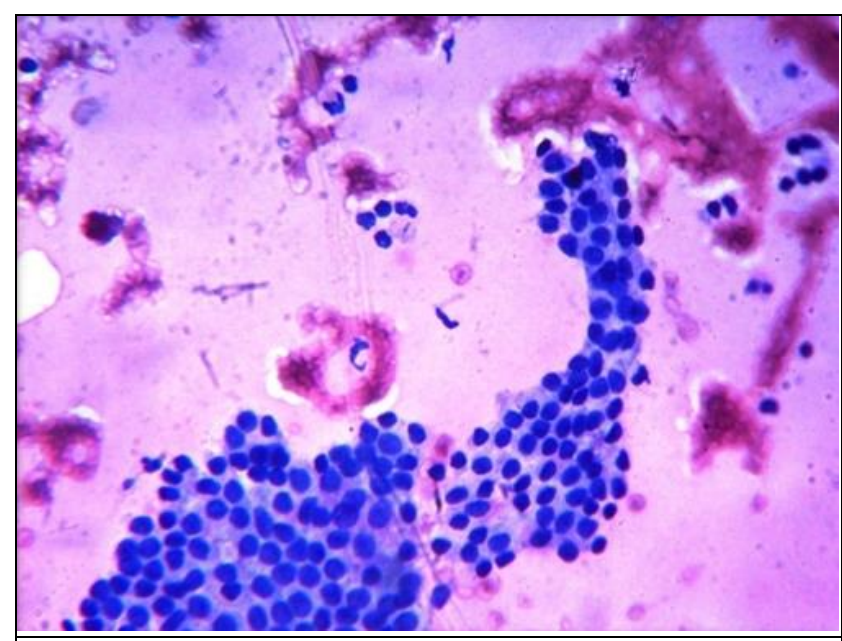

Figure 12. FNAC Smear Showing Papillary Fronds with Anatomical Edging H\&E $\times 100$

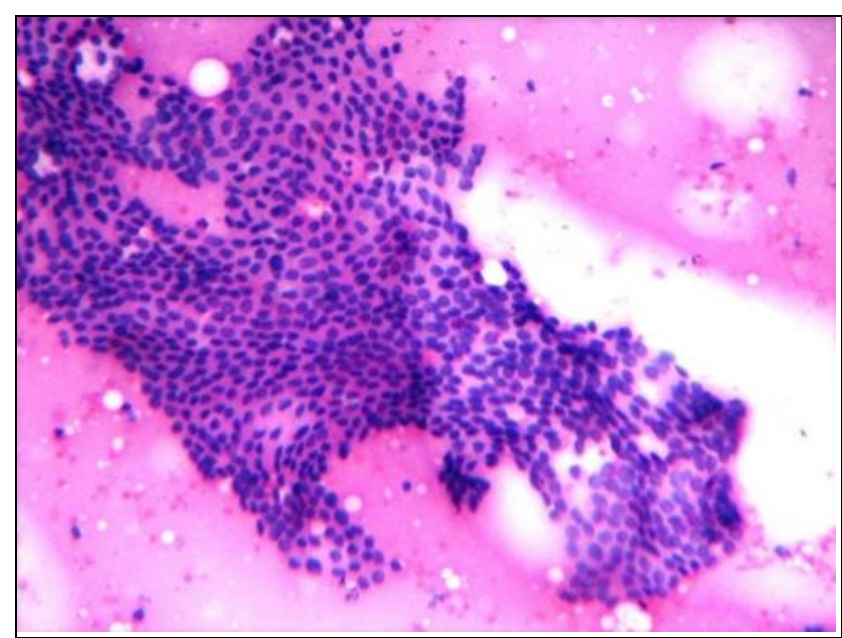

Figure 13. FNAC Smear Showing Papillary Fronds with Anatomical Edging H\&E x100 


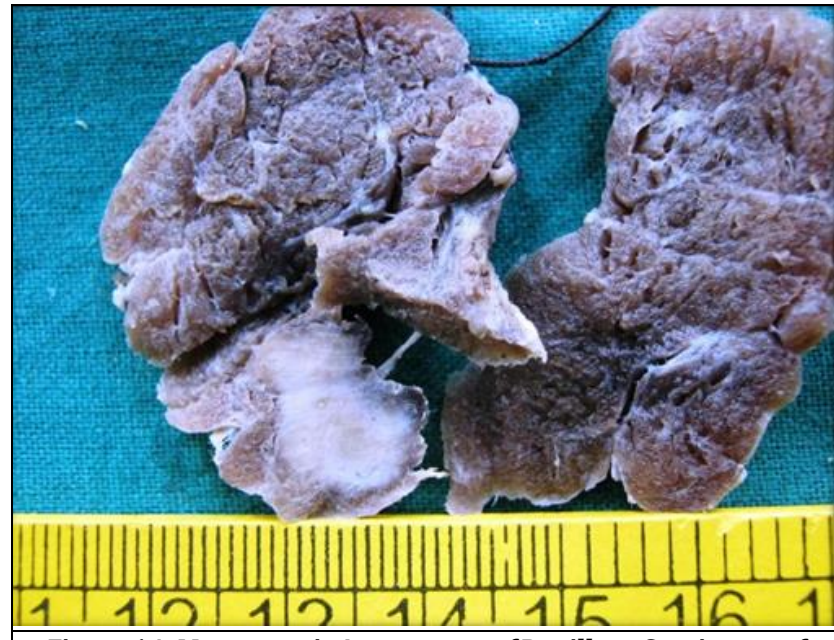

Figure 14. Macroscopic Appearance of Papillary Carcinoma of Thyroid Showing Focal Greyish White Tumour
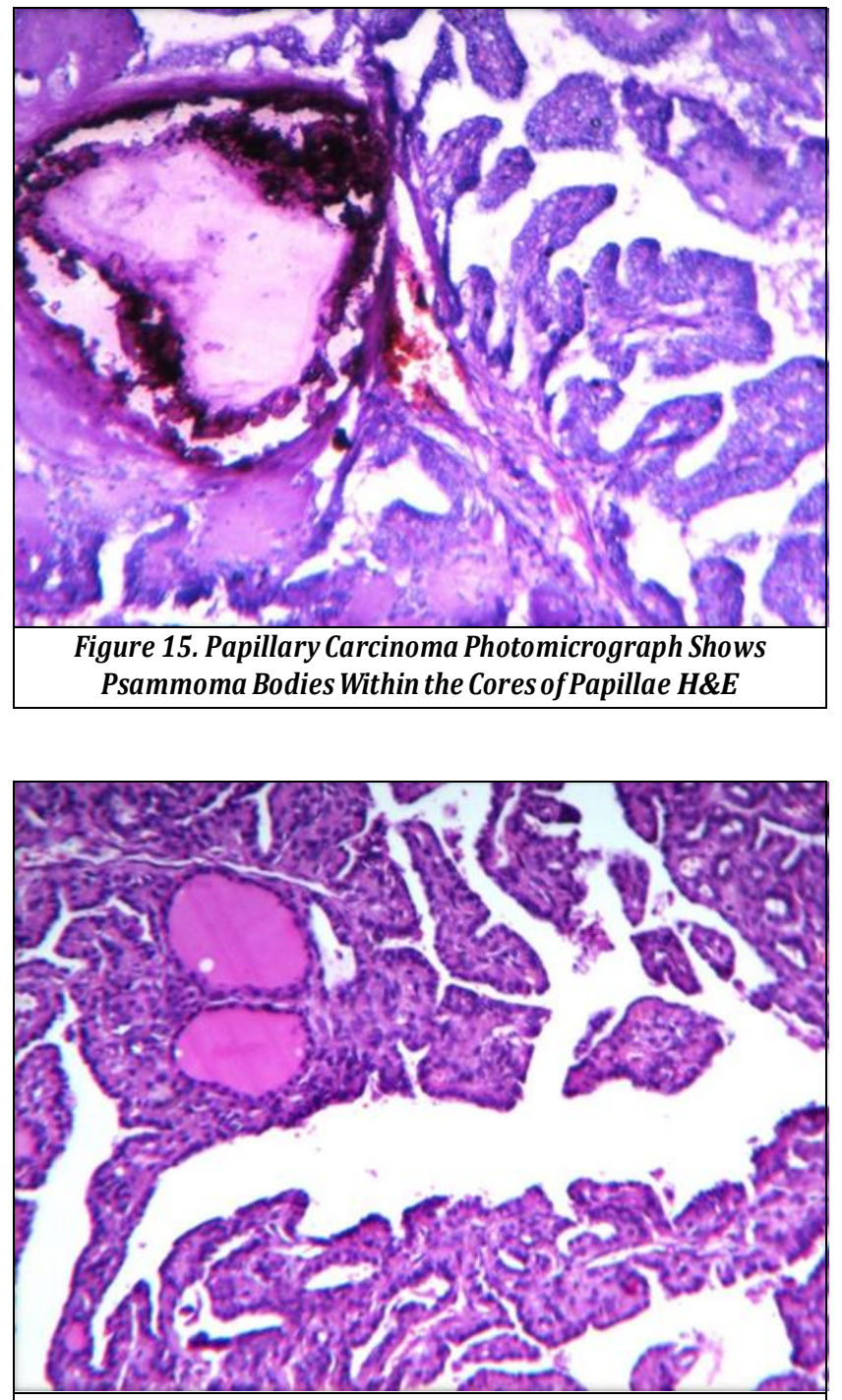

Figure 16 Papillary Carcinoma:Photomicrograph Shows Branching Papillae Having a Fibrovascular Stalk Covered By a SingletoMultipleLayersofCuboidalEpithelialCells. H\&E x100

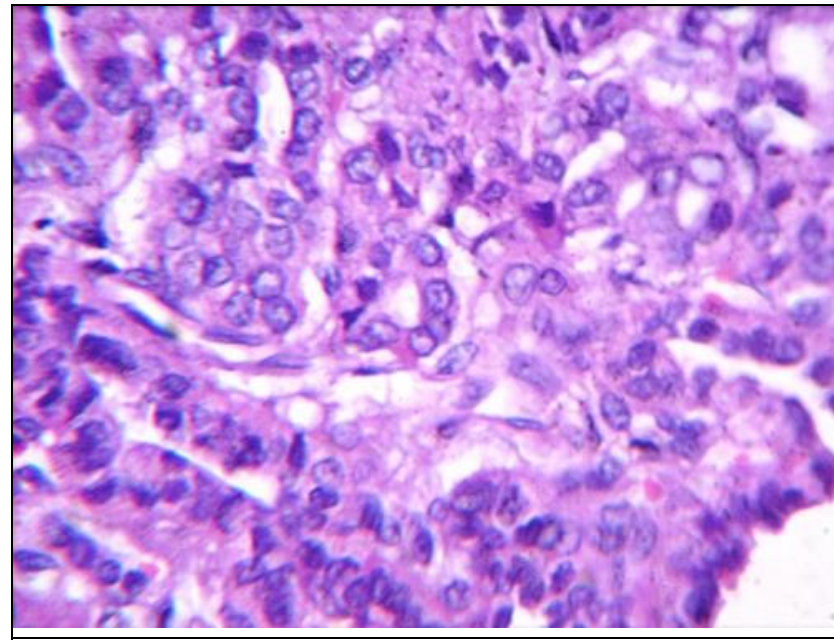

Figure 17. ThenucleiofPapillaryCarcinomaCells Contain Finely Dispersed Chromatin, WithanOptically ClearOrEmpty Appearance (Orphan Annie Eye Nuclei) H\&E)
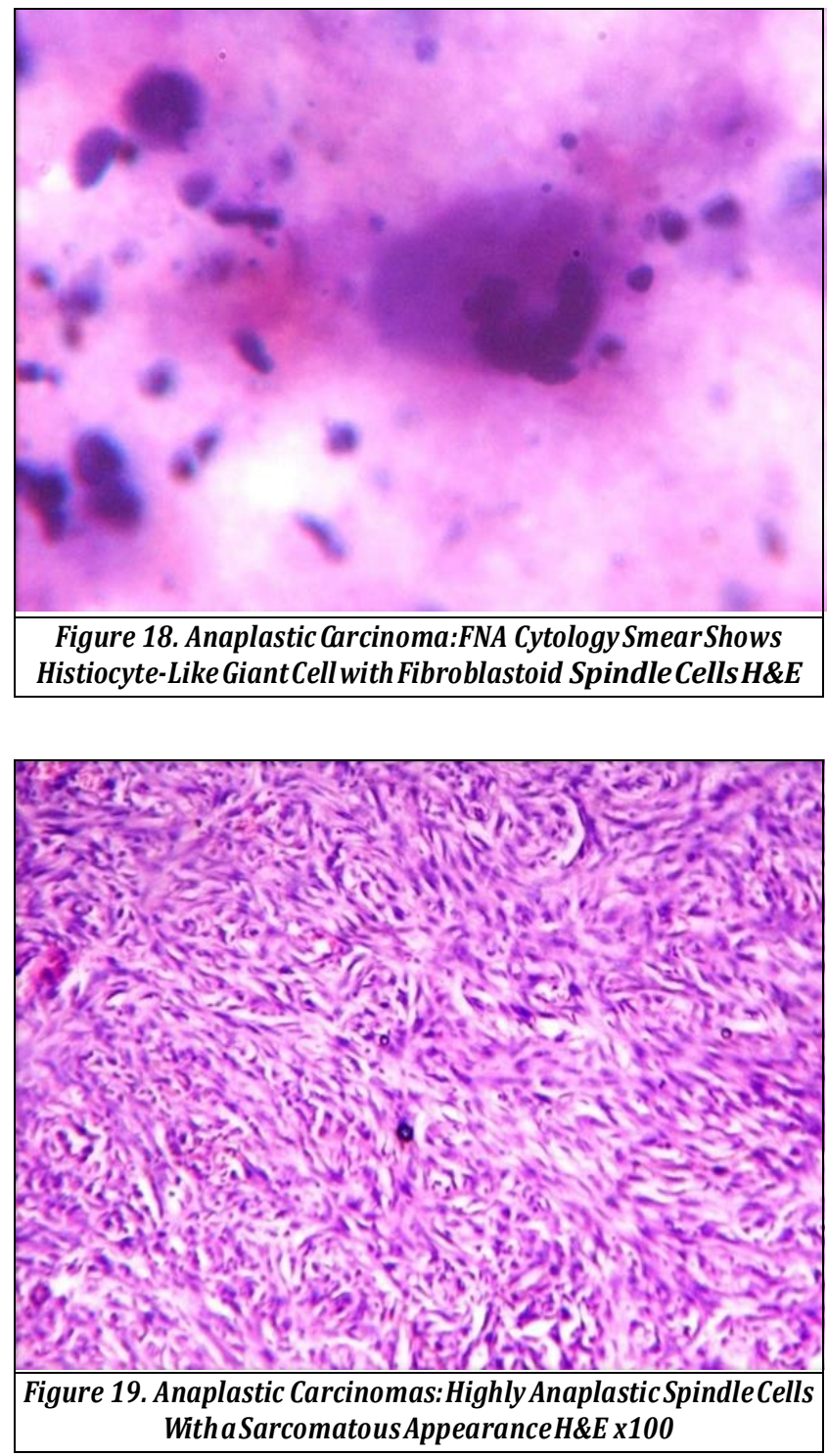


\section{CONCLUSION}

Fine Needle Aspiration Cytology is a cost effective, simple, rapid, almost noninvasive, and an efficient method in differentiating benign and malignant lesions. With the aid of FNAC unnecessary surgical procedures can be reduced.

\section{REFERENCES}

[1] Pepper GM, Zwickler D. Rosen Y. Fine-needle aspiration biopsy of the thyroid nodule. Results of a start-up project in a general teaching hospital setting. Arch Intern Med 1989;149(3):594-6.

[2] Dorairajan N, Jayashree N. The role of fine needle aspiration in solitary nodule of the thyroid and in the management of solitary thyroid nodule. Professional Med J 2006;13(4):596-603c.

[3] Nnagada HA, Musa AB, Gali BM, et al. Fine needle aspiration cytology of thyroid nodules. A Nigerian tertiary hospital experience. The Internet Journal of Cardiovascular Research 2006.

[4] Gupta C, Sharma VK, Agarwal AK, et al. Fine needle aspiration cytology of solitary nodule of thyroid and its histopathological correlation. Journal of Cytology 2001;18(3):151-6.

[5] Kaur K, Sonkhya N, Bapna AS, et al. A comparative study of fine need aspiration cytology, ultrasonography and radionuclide scan in the management of solitary thyroid nodule: a prospective analysis of fifty cases. Indian Journal of Otolarngology and Head and Neck Surgery 2002;54(2):96-101.

[6] Hurtado-Lopez LM, Arellano-Mantanos S, TorresAcosta EM, et al. Combined use of fine needle aspiration biopsy. MIBI scans and frozen section biopsy offers the best diagnostic accuracy in the assessment of the hypofunctioning solitary thyroid nodule. Eur J Nucl Med Mol Imag 2004;31(9):1273-9.

[7] Muddegowda PH, Lingegowda JB, Hiremath SS, et al. Panorama of solitary thyroid nodule. International Journal of Medical and Health Sciences 2012;1(1):1926.
[8] Welker MJ, Orlov D. Thyroid nodules. American Family Physician 2003;67(3):559-66.

[9] Cheung YS, Poon CM, Mak SM, et al. Fine-needle aspiration cytology of thyroid nodules: How well are we doing? Hong Kong Med J 2007;13(1):12-5.

[10] Mundasad B. Mcallister I, Carson J, et al. Accuracy of Fine- needle aspiration cytology in diagnosis of thyroid swelling. The Internet Journal of Endocrinology 2006;2:1-4.

[11] Suresh K, Shakil A, Abdullah D. Role of FNAC in thyroid disease. Journal of Surgery Pakistan (International) 2008;13(1):24-5.

[12] Swamy GG, Madhuravani S, Swamy GM. Fine needle aspiration cytology: a reliable diagnostic tool in the diagnosis of thyroid gland enlargements. Nepal Med Coll J 2011;13(4):289-92.

[13] Gupta M, Gupta S, Gupta VB, et al. Correlation of FNAC with histopathology in the diagnosis of solitary thyroid nodule. Article ID 379051, Journal of Thyroid Research 2010;2010: p. 5.

[14] Nzegwu MA, Njeze GE, Olusina DB, et al. A histological update of thyroid lesions in Enugu, Nigeria: a 5-year retrospective study. Asian J Exp Biol Sci 2010;1(2):430-3.

[15] Harach HR, Zusman SB, Saravia DE. Nodular goiter: a histo-cytological study with some emphasis on pitfalls of fine needle aspiration cytology. Diagnostic Cytopatholology 1992;8(4):409-19.

[16] Kunori T, Shinya H, Satomi T, et al. Management of nodular goiters and their operative indication. Surgery Today 2000;30(8):722-6.

[17] El Hag IA, Kollur SM, Chiedozi LC. The role of FNA in the initial management of thyroid lesions: 7-years of experience in a district general hospital. Cytopathology 2003;14(3):126-30.

[18] Mathur SR, Kapila K, Verma K. Role of Fine needle aspiration cytology in the diagnosis of goiter. Indian J Pathol Microbial 2005;48(2):166-9. 